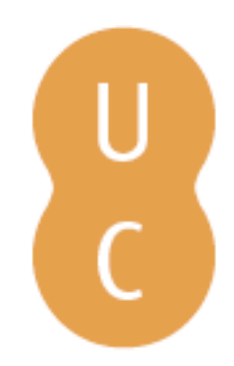

\title{
pommalina
}

\section{Projeto de escola de ténis}

Autor(es): $\quad$ Mendes, Pedro Cabral; Gomes, Ricardo; Damásio, António S.

Publicado por: Imprensa da Universidade de Coimbra

URL

persistente: URI:http://hdl.handle.net/10316.2/41765

DOI: $\quad$ DOl:https://doi.org/10.14195/978-989-26-1286-7_4

Accessed : $\quad$ 26-Apr-2023 07:36:44

A navegação consulta e descarregamento dos títulos inseridos nas Bibliotecas Digitais UC Digitalis, UC Pombalina e UC Impactum, pressupõem a aceitação plena e sem reservas dos Termos e Condições de Uso destas Bibliotecas Digitais, disponíveis em https://digitalis.uc.pt/pt-pt/termos.

Conforme exposto nos referidos Termos e Condições de Uso, o descarregamento de títulos de acesso restrito requer uma licença válida de autorização devendo o utilizador aceder ao(s) documento(s) a partir de um endereço de IP da instituição detentora da supramencionada licença.

Ao utilizador é apenas permitido o descarregamento para uso pessoal, pelo que o emprego do(s) título(s) descarregado(s) para outro fim, designadamente comercial, carece de autorização do respetivo autor ou editor da obra.

Na medida em que todas as obras da UC Digitalis se encontram protegidas pelo Código do Direito de Autor e Direitos Conexos e demais legislação aplicável, toda a cópia, parcial ou total, deste documento, nos casos em que é legalmente admitida, deverá conter ou fazer-se acompanhar por este aviso.

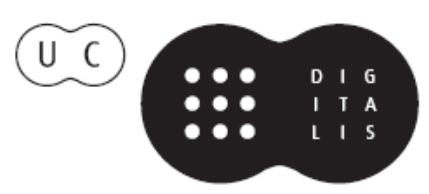


IMPRENSA DA UNIVERSIDADE DE COIMBRA

COIMBRA UNIVERSITY PRESS

RAUL A.

MARTINS

GONÇALO DIAS

PEDRO CABRAL MENDES

\section{EDITORES}

ESTRATÉGIA

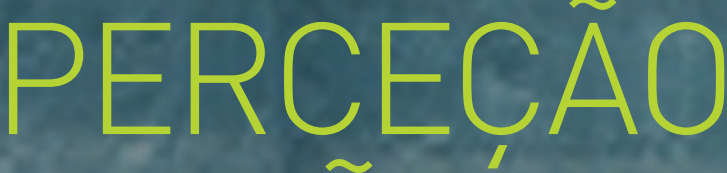

EAGÃA

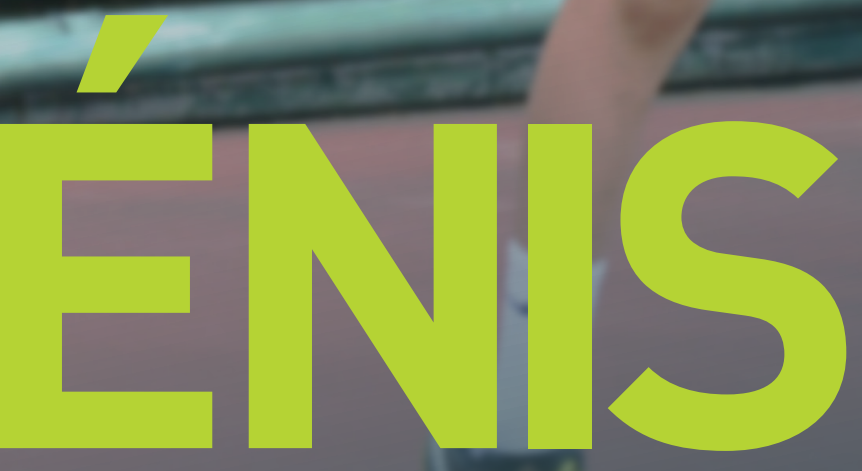




\title{
CA P Í T ULO 4 \\ PROJETO DE ESCOLA DE TÉNIS
}

\author{
Pedro Cabral Mendes \\ Ricardo Gomes \\ António S. Damásio
}

\section{Introdução}

O presente trabalho tem como objetivo apresentar a conceção de um modelo organizacional para clubes de ténis numa estratégia dinâmica de futuro. A proposta apresentada neste capítulo sustenta-se numa visão de desenvolvimento da prática do ténis assente numa dinâmica estrutural que integre as vertentes formativa, competitiva e de lazer. Sabe-se, no entanto, que a relação entre estas três vertentes nem sempre é articulada da melhor forma nos clubes desportivos, academias e demais entidades responsáveis pelo desenvolvimento da modalidade, o que coloca desafios adicionais. Assim, nesta proposta de modelo de organização de uma escola de ténis, exploram-se todas as potencialidades que a modalidade oferece ao jogador, tais como: a promoção de relações sociais entre elementos da escola e fora dela; a possibilidade de prática intergeracional; a competição e o lazer; o jogo ao ar livre; a aquisição de comportamentos e atitudes consentâneos com a prática desportiva, no âmbito das normas do espírito desportivo e no respeito por um código de conduta implícito à prática 
do ténis. Pretende-se, deste modo, consubstanciar nesta proposta a definição dos pressupostos, objetivos e modelo organizacional que corporizem toda a riqueza associada à prática desta modalidade.

Este modelo de escola baseia-se igualmente numa matriz pentadimensional de geometria variável de Gustavo Pires (1994) e que integra 5 dimensões: jogo, movimento, agonística, institucionalização e projeto. O jogo agrega a competição, a sorte, o simulacro, ordem, desordem e vertigem, características que estão presentes na vertente formação de base prevista neste modelo organizacional de clube.

As componentes do movimento enquadram-se na vertente de formação utilitária, marcadamente direcionada para o desenvolvimento e/ ou manutenção das capacidades motoras e da aquisição do repertório técnico-tático da modalidade de ténis de campo. A vertente formativa e a utilitária estão configuradas de forma a assegurar que os potenciais praticantes tenham prazer e gosto pela prática do ténis. No contexto dos fatores decisivos para a adesão à prática desportiva num mundo ocidental marcado pelo envelhecimento demográfico, Lee (1999) alerta para a necessidade das instituições desportivas se recentrarem no ideal 'jovens para o desporto' e não 'desporto para os jovens', assegurando prazer e gosto pela prática desportiva a quem a procura.

As componentes da Agonística que, segundo Pires (1994), compreendem a agressividade, a tensão, a supercompensação complemento, a supercompensação superação, a supercompensação substituição, o exibicionismo e a motivação, estão presentes na vertente competitiva deste modelo organizacional. Nesta dimensão, a lógica dominante é a performance desportiva, onde o sacrifício, o rigor, a superação, suplantam o prazer, o lazer, o lúdico.

A dimensão institucional do desporto ao ter como componentes os sistemas de valores, os sistemas de interesses, as tradições, o legal, o ilegal, os compromissos, reflete de alguma maneira as normas específicas e conhecidas na organização do desporto, pelo sistema desportivo, educativo e pela própria sociedade onde se insere o clube. 
A quinta dimensão proposta por Pires (1994), o projeto, permite modelar a geometria do processo de desenvolvimento desportivo, abrangendo componentes que vão desde a definição dos objetivos, estratégias, aos programas, à execução e às correções.

O modelo organizacional aqui apresentado também se fundamenta nas propostas de organização de clubes/escolas de ténis da Real Federação Espanhola de Ténis (2003a 2003b), Federação Francesa de Ténis (1987, 1989) e da Associação de Ténis dos Estados Unidos (USTA, 2004). A proposta organizacional define as suas finalidades e funções, o seu posicionamento no sistema desportivo e educativo português, a natureza do serviço que presta e respetivo financiamento, a sua orgânica, os perfis dos potenciais praticantes, a organização do processo formativo e da programação do ensino nos diferentes níveis de treino.

Este modelo pretende ser flexível e articulável entre os diversos elementos que o compõem contrariando quer a visão unidimensional do desporto nas academias de ténis, onde só existe espaço para a performance, quer a lógica organizacional de matriz bipolar ou bidimensional dos clubes tradicionais de ténis, excessivamente direcionados para a massificação da modalidade ao serviço do rendimento.

Este esforço de síntese é resultado das vivências em ambientes de prática desta modalidade, para além do conhecimento das necessidades inerentes ao processo de desenvolvimento do praticante em todas as fases da sua vida desportiva. Visa-se com este capítulo responder à seguinte questão: qual o modelo de escola de ténis de campo que assegura o desenvolvimento de todas as vertentes associadas à prática desta modalidade?

\section{Enquadramento do projeto escola de ténis}

A definição de um modelo organizacional de escola de ténis é contemplada nos programas de formação dos técnicos/treinadores 
desta modalidade desportiva por parte da Real Federação Espanhola de Ténis (2003a, 2003b), Federação Francesa de Ténis (1987, 1989) e Associação de Ténis dos Estados Unidos (USTA, 2004). No caso português, embora este tópico não seja alvo de abordagem nos pro-

gramas de formação dos técnicos da modalidade, é de destacar o contributo de Carvalho (1991) para uma conceção de escola, muito próxima do modelo francês.

Partindo dos modelos existentes e entendendo a escola de ténis numa perspetiva de Projeto Educativo, delimitou-se o Projeto de Escola de Ténis (PET) com base nos seguintes princípios: a) finalidades e funções da escola de ténis; b) posicionamento do projeto escola no sistema desportivo e educativo português; c) natureza do serviço; d) orgânica; e) perfis de praticante; f) organização do processo de formação e; g) orientações de programação para diferentes perfis de praticantes.

\section{Finalidades e funções da escola}

Essencialmente vocacionada para a promoção e desenvolvimento da prática do ténis, esta proposta assenta num conjunto de finalidades a perseguir por todos os agentes (praticantes, técnicos, pais e dirigentes, entre outros). Assim, deve assegurar-se em todas as etapas do processo de formação, nas vertentes desportiva, personalizadora e socializadora, que a convergência de esforços seja perspetivada de forma holística e integradora, contribuindo deste modo para o desenvolvimento global do praticante de ténis.

A conceção de escola de ténis vertida neste texto pode servir de referência para um clube ou associação, com ou sem estatuto de utilidade pública, ou pode ser adotada para uma academia. De facto, o PET está estruturalmente desenhado para dar resposta à iniciação desportiva em idades mais baixas, ou aqueles que mais 
tarde se iniciam no Ténis, à vertente competitiva e aqueles cuja prática "órbita" apenas na ótica do lazer.

\section{Posicionamento do projeto escola no sistema desportivo e educativo português}

No que concerne à oferta existente no plano do fomento para o ténis, e para além do subsistema de prática federado, há que considerar a oferta do Sistema Educativo (SE). Apesar de o Ténis não estar contemplado nos programas de Educação Física do $2{ }^{\circ}$ Ciclo do Ensino Básico, esta matéria de ensino tem sido alvo de uma abordagem crescente por um número significativo de profissionais de Educação Física neste ciclo de ensino. Relativamente aos restantes níveis de ensino, o ténis faz parte do programa de EF do $3 .^{\circ}$ Ciclo do Ensino Básico e Secundário, no âmbito das atividades físicas desportivas - desportos de raquetes. Para além desta oferta, no ensino básico (2..$^{\circ}$ e $3{ }^{\circ}$ Ciclos) e secundário existe a possibilidade de praticar Ténis sob a égide do Desporto Escolar, nos Clubes de Desporto Escolar e Centros de Formação Desportiva (CFD). Segundo dados gentilmente fornecidos pela Direção Geral de Educação - Gabinete de Desporto Escolar, existem 40 CFD em funcionamento no País (2015/16) e nenhum contempla o ténis de campo. Relativamente aos grupos equipa, são atualmente $153 \mathrm{em}$ atividade no território português. Sobre esta oferta desportiva, o programa Nacional do Desporto Escolar ao estipular uma carga horária teórica de 3 horas semanais e um limite mínimo de 18 inscritos por grupo equipa, promove a necessária e desejável massificação da modalidade mas compromete a progressão do praticante e a qualidade da sua formação.

Uma escola de ténis pode e deve estabelecer parcerias com escolas de proximidade no sentido de promover o fomento da modalidade no meio escolar, cedendo recursos materiais (bolas e raquetes), 
equipamentos (instalações desportivas, courts) e apoio técnico qualificado. São vários os exemplos em Portugal deste tipo de colaboração, referindo-se a título de exemplo o caso de Coimbra, onde o Clube Ténis de Coimbra e a Secção de Ténis da Associação Académica de Coimbra se têm articulado regularmente com os Clubes de Desporto Escolar das escolas do concelho, com grupos equipa nesta modalidade, facilitando-lhes o acesso às suas instalações para a realização das jornadas relativas aos quadros competitivos desses grupos equipa. Protocolos desta natureza entre clubes federados e as escolas podem potenciar o "aparecimento" de novos praticantes, enquanto ações de massificação da prática do Ténis, funcionando deste modo como potenciais sistemas de alimentação nos clubes.

No âmbito do rendimento, a articulação entre os sistemas desportivo e educativo ganha outra relevância e urgência no contexto português atual. A adaptação do horário escolar dos jovens com perfil de rendimento à carga de treino semanal assume, nos dias de hoje, uma enorme importância no seu percurso desportivo e educativo. Dito de outro modo, a necessidade de uma correta distribuição diária e semanal das sessões de treino, muitas vezes em regime bidiário, torna-se imprescindível na organização do treino no ténis, seja por necessidade de maior tempo de prática, seja por necessidade de repartir as cargas/volume de treino por forma a proporcionar adequados tempos de recuperação ao praticante. Contudo, até ao momento, o quadro legal existente não permite flexibilizar o horário da carga letiva, de modo a que o atleta possa, por exemplo, treinar entre as $8 \mathrm{~h} 30$ e as $10 \mathrm{~h} 30$ e as $17 \mathrm{~h} 00-19 \mathrm{~h} 00$, todos os dias. As situações existentes são sustentadas em alguns centros de alto rendimento de algumas modalidades desportivas, mas com base em modelos de trabalho pouco adequados a um percurso de formação dual, educativa e desportiva, dos jovens.

$\mathrm{O}$ atleta de rendimento que pretende e deseja treinar e estudar, depara-se com inúmeros constrangimentos que extravasam as 
dificuldades de articulação dos treinos com as aulas. As ausências frequentes devido à participação em torneios durante a semana exigem da escola uma resposta tutorial que permita compensar parte das aulas perdidas durante esses períodos de tempo, algo que raramente acontece. A cooperativa de Ensino, Coimbra Sports Academy, em funcionamento desde 1 de setembro de 2014 tem procurado dar resposta a esta necessidade de articulação entre a escola, o Ministério da Educação e os clubes. O PET deve desenvolver ações que viabilizem soluções de conforto para os atletas de rendimento, em cooperação com a escola de forma a minorar as dificuldades e a cimentar compromissos entre as partes.

\section{Natureza do serviço vs financiamento}

Os serviços da escola centram-se, de um modo geral, na facilitação do acesso aos diferentes tipos de envolvimento na prática do ténis que os praticantes pretendem em função do seu nível de desempenho e dos objetivos individuais.

Partindo do pressuposto de que uma escola de ténis para ter sucesso deverá responder às expectativas dos seus "clientes», uma questão emerge: como satisfazer as motivações de um grupo tão heterogéneo de praticantes? A solução passa por garantir a todos os praticantes e potenciais praticantes desta modalidade a satisfação das suas necessidades que, apesar de diferentes, não são incompatíveis.

Nesta perspetiva, os praticantes ao nível de "formação utilitária" e de "formação base", que encaram o ténis mais como um meio de diversão ou como preparação para níveis mais elevados de prestação, são os grupos que podem suportar os custos adicionais dos praticantes envolvidos na competição e alto rendimento. Em consequência desta comparticipação, espera-se que os resultados desportivos obtidos pelos últimos funcionem como um veículo de promoção e divulgação da 
escola, contribuindo, por um lado, para captar novos praticantes e, por outro, atrair novos investidores (patrocinadores e/ou mecenas).

A participação em competições nos escalões de formação (sub12, sub14, sub16, sub18) exige um suporte financeiro adicional, geralmente custeado pelos pais, para despesas com materiais e equipamentos, inscrições, deslocações para os torneios e honorários com o enquadramento técnico. Qual será então o papel da escola relativamente aos melhores praticantes de que dispõe? A USTA (2004) defende que o sucesso duma escola de ténis depende, em certa medida, dos triunfos obtidos. Nesse sentido, a solução preconizada poderá passar pela criação de uma bolsa interna. Esta medida também é enaltecida pela FFT (1989), de forma a apoiar os praticantes no pagamento das inscrições, deslocações a torneios e a oferta de equipamentos (raquetes, cordas, vestuário, etc.). Caberá à escola a angariação de apoios a nível local, de forma a viabilizar a implementação das bolsas. O patrocínio e o mecenato desportivo são ainda outras ferramentas a considerar, caso a escola funcione num clube com estatuto de utilidade pública.

A outra aposta do PET deverá ser no tipo de praticante que se enquadre no perfil de jogador de base. Findo o seu processo de formação, o praticante domina as componentes do jogo, o que o capacita para a prática desta modalidade com correção e eficiência. Torna-se num potencial cliente para a escola e um importante interlocutor na dinâmica associativa do clube ou coletividade.

No caso de o aluno que opte pela via do lazer, apesar de não viver tão intensamente o ténis como os restantes, deve apostar-se na sua continuidade, incentivando-o e integrando-o nas dinâmicas da escola. Para este tipo de praticante, devem prever-se ações específicas no Plano de Atividades, centradas preferencialmente em atividades cuja principal característica seja a diversão e o convívio. As classes de lazer e de adultos são as mais lucrativas para a escola e imprescindíveis para garantir a sua sustentabilidade financeira, face aos custos da competição. 


\section{Orgânica do projeto de escola}

Entende-se a escola de ténis como uma organização onde as funções, os direitos, as motivações dos técnicos e dos praticantes e a forma como se relacionam são determinantes para o sucesso da mesma. É conveniente, por um lado, definir a orgânica da cadeia de decisão subjacente a este Projeto e, por outro, definir o tipo e natureza das competências de todos os atores organizacionais.

A fim de posicionar a direção do clube, do diretor da escola e do corpo técnico à luz de um processo decisório, partir-se-á dos elementos da organização identificados por Mintzberg (1989): Vértice Estratégico, Linha Hierárquica, Centro Operacional, Tecnoestrutura e Logística ou staff. Assumindo esta última como a parte da organização onde se “... organizam todos os serviços de suporte que não intervêm na produção..." (Pires, 2007, p. 206). Neste propósito, o staff fica responsável pelos serviços administrativos do PET.

A tecnoestrutura terá um peso reduzido na organização, tal como preconizado por Mintzberg (1989) para organizações com uma configuração estrutural do tipo empreendedora. Esta é caracterizada por um funcionamento simples, em virtude dos poucos níveis decisórios: direção, diretor da escola e corpo técnico.

Posicionada no vértice estratégico, a direção do clube/associação/ academia, deverá definir a estratégia apropriada para que se cumpra a vocação e a missão da organização. Será a direção a formular as políticas desportivas, a definir o projeto que se pretende implementar, as finalidades e a garantir a representação institucional (Figura 1).

$\mathrm{Na}$ linha hierárquica, encontra-se o cargo de diretor da escola, situado imediatamente abaixo da direção e cabendo-lhe um papel de coordenador, programador da estrutura técnico-pedagógica ligada à instrução, socializador e estimulador dos praticantes. As tomadas de decisão no âmbito da estrutura técnico-pedagógica terão repercussões em todos os níveis de treino, em virtude das mesmas serem de 
natureza programática, seletiva e organizacional, ou seja, condicionarão toda a ação interventiva da escola desde o primeiro ao último nível de formação.

Conforme resulta da 2 , verifica-se que o diretor da escola assume prioritariamente a competência consignada para a estrutura técnico-pedagógica, apesar de o corpo técnico ter voz no processo e a oportunidade e o dever de cooperar quer na elaboração do plano de atividades e dos programas, quer na constituição das classes e escalonamento dos praticantes por níveis de treino.

Os programas deverão ser construídos com base na estrutura do conhecimento defendida por Vickers (1990), estrutura essa que se alicerça em 4 categorias disciplinares: treino físico; conhecimento de base sobre a modalidade; destrezas psicomotoras/estratégias; e conceitos psicossociais. Estas quatro categorias deverão estar presentes ao longo dos programas, variando o grau de complexidade de cada uma delas. Um programa, independentemente do nível, deverá definir competências gerais e específicas e o protocolo de avaliação (teste de progressão de nível).

O direção e o corpo técnico, indo ao encontro do que é preconizado pela escola Espanhola. O diretor deverá assumir a responsabilidade dos contactos com pais ou associação de pais, gabinete de medicina desportiva, psicólogo, patrocinadores, comunicação social e secretaria (Figura 1). As suas funções são de natureza organizacional, supervisão, programação e de mediação, donde se infere que o funcionamento da escola a todos os níveis passará por si. O desempenho de um cargo desta importância pressupõe que o mesmo deva ser ocupado por alguém que tenha como habilitações mínimas o curso federativo de ténis de nível 2 e uma licenciatura em Gestão do Desporto e/ou Ciências do Desporto, a fim de fazer face à complexidade e abrangência das funções a desempenhar, para além do conhecimento profundo que deve ter sobre a modalidade.

Assumindo a posição ao nível do centro operacional, o corpo técnico deverá pôr em prática a programação traçada pelo órgão hierarquicamente superior, planeando e ensinando a modalidade de ténis. 
A dimensão do corpo técnico deverá variar consoante o número de praticantes e campos disponíveis. A atribuição de um determinado nível de treino a um treinador deve ter como requisito o seu nível de formação profissional. Assim, para os níveis de pré-iniciação, iniciação 1 e iniciação 2 propõe-se como habilitações mínimas o curso federativo de ténis de nível I e para as classes de aperfeiçoamento 1 e 2 e competição, o curso federativo de nível II. Relativamente ao batedor (sparring), não lhe é exigido qualquer curso de formação, mas sim que tenha um bom nível de jogo, uma vez que a sua principal função será a de melhorar o ritmo de jogo dos praticantes de competição.

As funções dos técnicos passam pela aplicação dos programas, planeamento, controlo e avaliação do treino, intervenção técnico-pedagógica no court e acompanhamento dos praticantes em torneios.

A escolha de um batedor deverá ter em consideração o seu percurso desportivo (um ranking sénior acima dos primeiros 50 lugares e resultados desportivos relevantes de âmbito regional e/ou nacional), a sua formação no respetivo clube e um perfil de jogador de formação competitiva preconizado pelo PET.

A política desportiva a definir deverá basear-se em medidas e ações que respondam às expectativas de todos os frequentadores e praticantes do PET. Nesse sentido, elaborou-se um espetro motivacional de onde se destacam 3 tipos de praticantes: $i$ ) entretenimento (perfil de formação utilitária); ii) formação de base; iii) formação competitiva.

\section{Perfis de praticante}

Durante o processo de formação, que pode oscilar entre os 4 e 8 anos, pretende-se assegurar três tipos de perfis: formação utilitária; formação base e formação competitiva.

O praticante de formação utilitária procura ocupar o tempo livre, podendo encontrar-se dois subgrupos: um constituído pelas crianças 
e jovens e um outro por adultos jovens e seniores. A população infanto-juvenil, por norma, é encorajada pelos pais para a necessidade de praticar um desporto, de forma a melhorar a sua condição física. Por outro lado, o envolvimento na prática pela população adulta e sénior é influenciado tendencialmente pela família e amigos.

Relativamente ao praticante de formação de base, a opção pelo ténis foi um desejo, uma vez que gosta da modalidade ou está sensibilizado para a sua prática. As competências adquiridas na formação de base devem permitir ao praticante o domínio dos gestos técnicos fundamentais e dos princípios táticos básicos em situação de jogo, o desenvolvimento das capacidades volitivas e psicológicas e o conhecimento do quadro regulamentar da modalidade.

Por último, o praticante de competição é um amante incondicional da modalidade, gosta por natureza de competir e demonstra frequentemente predisposição para a prática do ténis. O praticante na vertente competitiva deve dominar os gestos técnicos de situação e especiais, bem como os princípios táticos competitivos no jogo de singulares e de pares. Refira-se ainda que este tipo de praticante, com perfil de rendimento, deve evidenciar competências emocionais e psicológicas que lhe garantam autonomia e sucesso desportivo.

\section{Organização do processo de formação no projeto escola}

Comparativamente com o modelo francês, onde a organização do ensino assenta em 2 blocos, centro de treino e o corredor de formação que engloba as estruturas escola e centro de aperfeiçoamento, esta proposta cria mais um bloco ou vertente formativa: as classes de adultos e de entretenimento. Os perfis de aluno com formação de base e competitiva enquadram-se na progressão do aluno ao longo dos vários níveis de treino (Figura 1). 
Relativamente aos praticantes novos que pretendam ingressar na escola, serão submetidos a um dos 4 testes existentes (Figura 3). A escolha do teste a aplicar é da responsabilidade do diretor da escola, que após uma avaliação inicial ao nível de jogo do candidato, decide qual o teste mais indicado. No que concerne aos adultos e praticantes de entretenimento, apenas estes poderão candidatar-se aos níveis de iniciação 1, iniciação 2 e aperfeiçoamento 1. A decisão sobre qual o teste a realizar pelo aluno é da inteira responsabilidade do técnico que leciona a classe de entretenimento. O facto de ser vedado aos praticantes das classes de adultos a entrada em qualquer nível de treino de formação de base justifica-se pela diferença de idades entre adultos e praticantes infanto-juvenis ( 9 aos 14 anos).

A partir da interpretação da Figura 3, verifica-se de igual modo que os praticantes podem circular pelas 3 vertentes de formação e nos dois sentidos: um aluno do entretenimento pode transitar por exemplo para a iniciação 2 e vice-versa e um aluno do aperfeiçoamento 1 ou 2 pode ingressar na competição e o contrário também. Qualquer transição ou progressão de nível, o praticante é sempre submetido a um teste.

A movimentação dos praticantes, dos níveis de formação de base para o nível de competição e vice-versa, deverá assentar na organização de um "torneio escada" a partir do qual qualquer aluno poderá entrar na competição desde que frequente o aperfeiçoamento 1 ou 2 .

A organização de um torneio escada, segundo a USTA (2004), implica uma ordenação hierárquica decrescente dos praticantes em função do seu nível de jogo. Para isso, propõe-se a realização de uma jornada round robin (todos contra todos), a fim de se seriar a totalidade dos praticantes do primeiro ao último classificado.

A progressão de níveis prevista para o PET é similar à preconizada pela FFT (1987) e FPT (1999). O modelo Francês norteia 
os 2 anos da estrutura da escola (equivalente à iniciação) com subníveis de duração de um trimestre. Esta proposta de progressão em muito se assemelha às graduações no judo, karaté e até mesmo às escolas de esqui. As vantagens na adoção deste tipo de progressão no ténis são várias:

- As crianças facilmente se motivam, pois identificam com facilidade as metas a atingir semestre a semestre. A entrega de um pin ou dístico, para cada nível superado, pode empenhar ainda mais os praticantes com vista a receberem o troféu comprovativo do seu nível técnico atingido;

- Dá fiabilidade e legitimidade ao processo de progressão dos praticantes, visto que a transição de um nível para outro pressupõe que os candidatos obtenham uma nota mínima nas provas constituintes do teste;

- Permite aos técnicos o controlo periódico da eficácia do seu modo de ensinar;

- Visibilidade à escola. Os pais e praticantes comentam dentro e fora do clube, sobre o profissionalismo e rigor do processo de avaliação que norteia a escola de formação.

A transição de um nível para outro pressupõe a realização de um teste ( $1 .^{a}$ chamada), podendo este ser repetido caso o candidato não obtenha uma classificação positiva $\left(2{ }^{\mathrm{a}}\right.$ chamada). A superação de qualquer teste premiará o praticante com um chapéu, t-shirt ou polo no ingresso de um novo nível de treino.

A realização de um Plano de atividades que promova o convívio entre pais, sócios, praticantes, elementos diretivos e técnicos e a prática de outras disciplinas desportivas, poderá ter um efeito catalisador de intenções pró-ativas relevantes para um funcionamento eficaz do PET. 


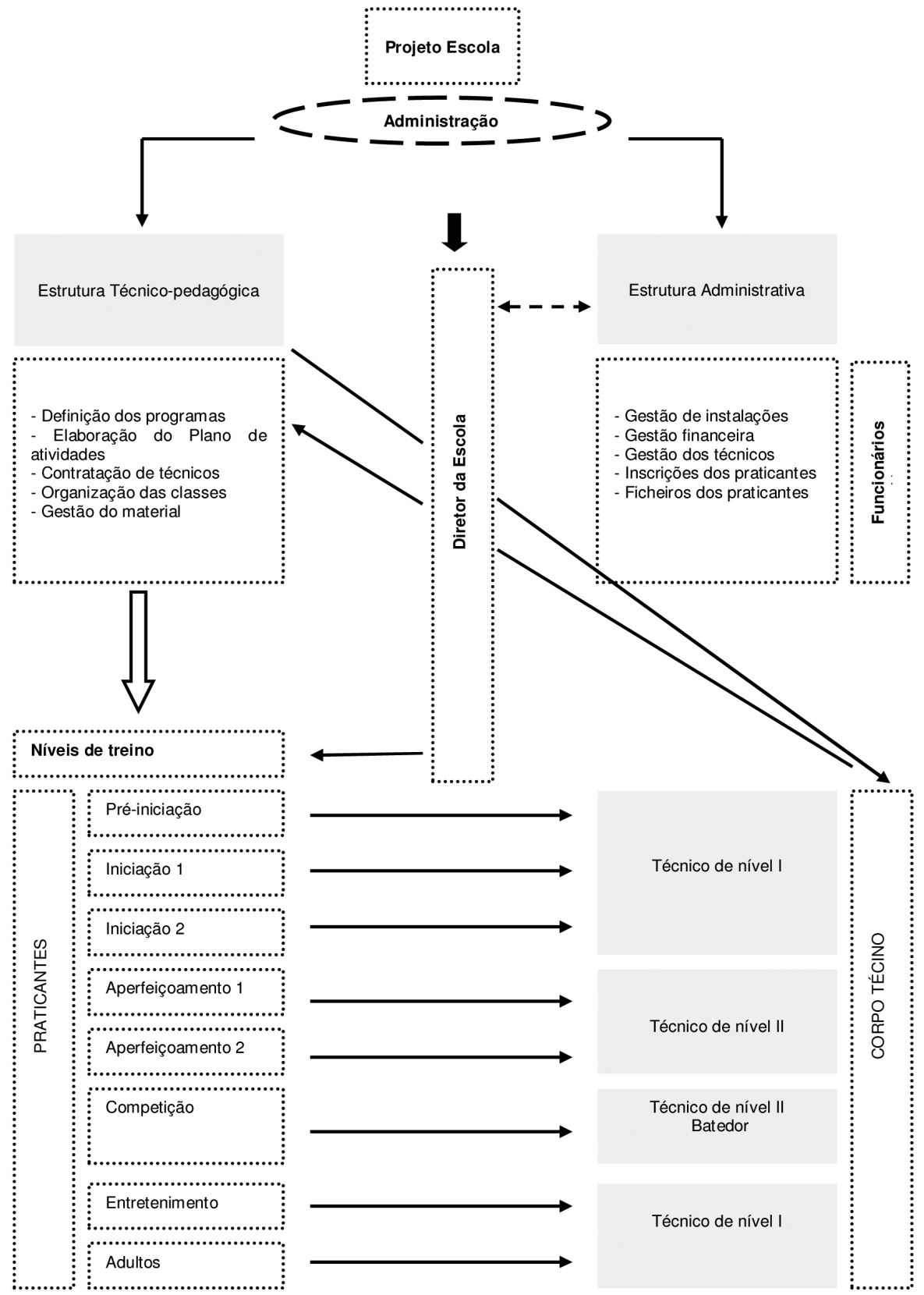

Figura 1. Os atores do Projeto Escola de Ténis 


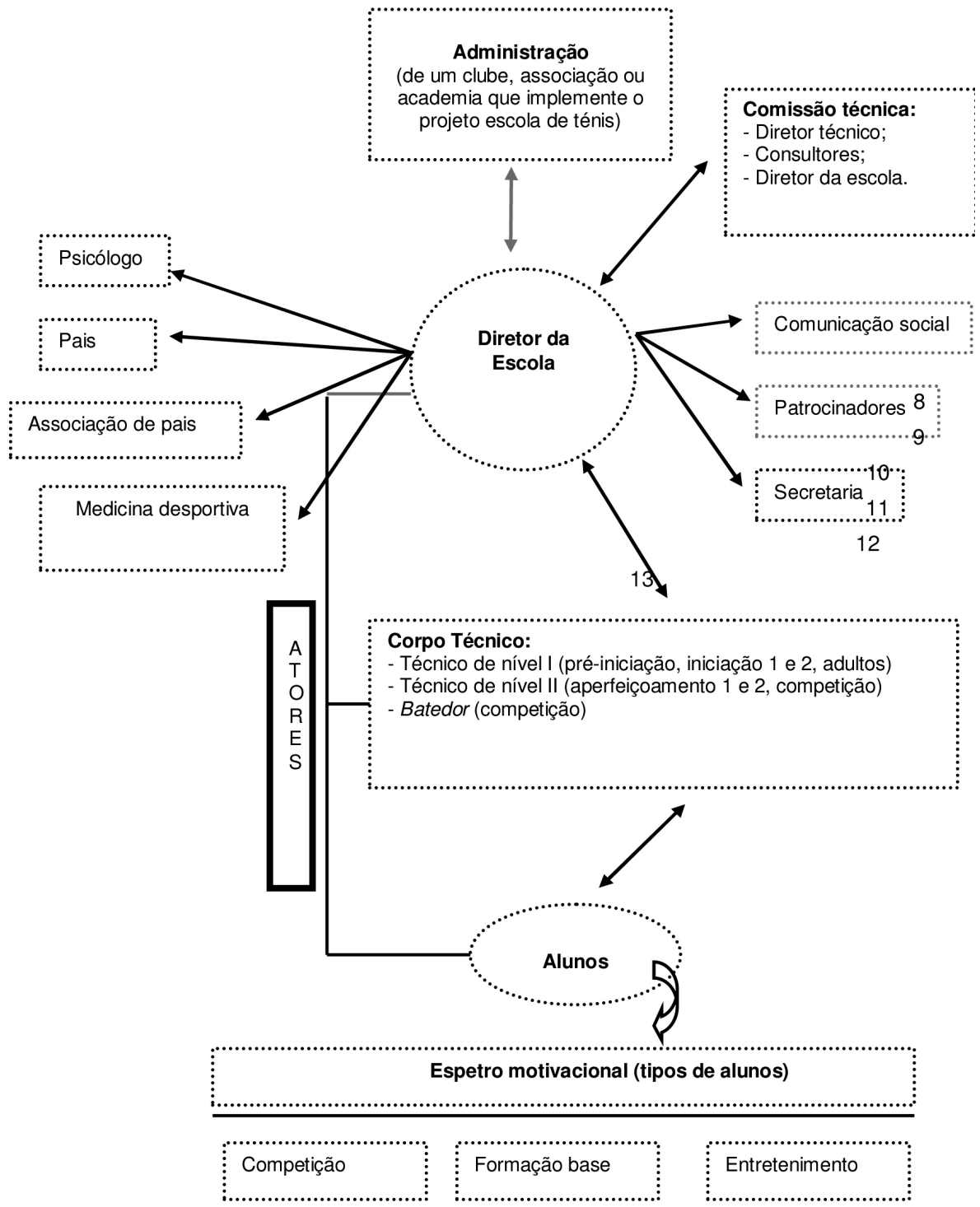

Figura 2. As estruturas do Projeto Escola de ténis 


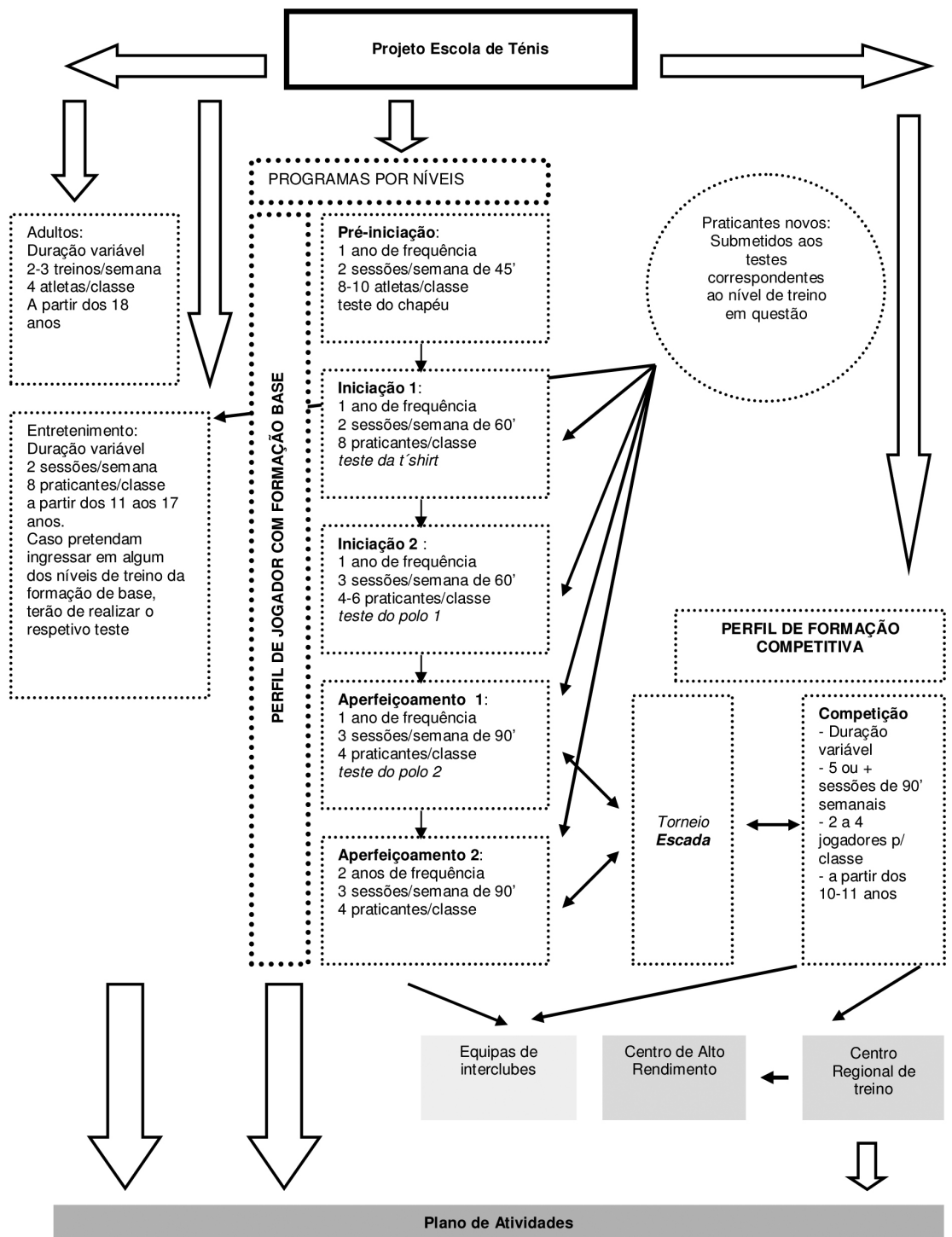

Figura 3. Organização do processo de formação do projeto escola 


\section{Organização da programação dos diferentes níveis de treino}

Os modelos de escola francesa (1989) e espanhola (2003a, 2003b) defendem a delimitação clara dos diferentes níveis de treino com base na frequência semanal o intervalo de idades aconselháveis à frequência dos vários níveis de treino e a duração de cada sessão. A Tabela 1 materializa a proposta de organização dos diferentes níveis de treino para o PET. As orientações previstas nos referidos modelos são aqui respeitadas: o decréscimo gradual do número de praticantes por classe, aliado ao acréscimo do volume total de treino, fruto quer do aumento da duração da sessão quer da frequência semanal. Esta estratificação do processo de formação em níveis, baseada tanto em intervalos etários suficientemente amplos para a desejada confluência com a idade biológica de cada praticante como no aumento sustentado da carga de treino, permite ir ao encontro dos modelos de formação desportiva de Bompa (1999), Martin e colaboradores (2001) e de Balyi (1993).

A definição do tipo de bola e as dimensões do espaço de prática para cada nível potenciam a aprendizagem diferencial de Schöllhorn (2008) e o entendimento do treino num princípio de mutualidade entre o corpo (praticante) e o ambiente (espaço de aprendizagem). Por outras palavras, as condições e os meios de treino deverão ajustar-se às características morfológicas e ao desempenho técnico do praticante (Tabela 1). Nesta linha de pensamento, a Federação Internacional de Ténis desenvolveu o programa: Play and Stay (Davids e col., 2010), promovendo assim uma pedagogia não-linear na abordagem ao ténis nos primeiros anos de prática. Refira-se ainda que este programa tem sido concretizado pela Federação Portuguesa de Ténis, a partir do Plano Nacional de Deteção de Talentos e do Circuito Smash Tour sub10. Face ao exposto, este tipo de metodologia de ensino pretende encorajar os treinadores para o ensino/treino a partir do jogo, secundarizando as abordagens lineares assentes unicamente na técnica (Farrow \& Reid, 2010). 


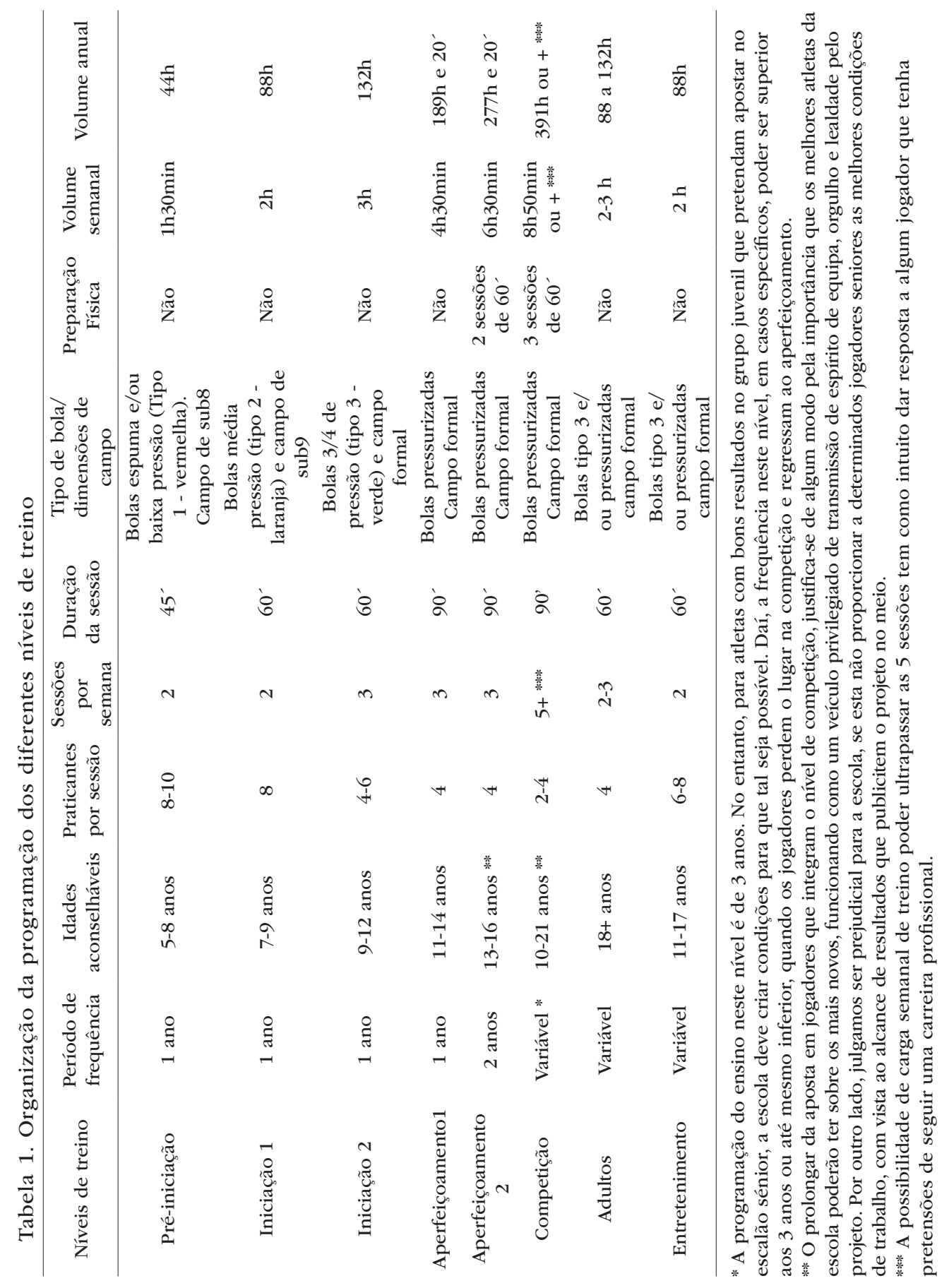




\section{Conclusão}

A construção de um Projeto de Escola de Ténis com base numa perspetiva transformacional não pode ser entendida como o início e o fim de um ciclo, mas sim como um começo de uma longa caminhada que passa obrigatoriamente pela sua adoção no meio, avaliação e reformulação.

Este Projeto deve ser entendido como uma proposta de estruturação do processo de formação no ténis de campo e como tal, a sua possível adoção deve ocorrer de uma forma flexível, entrando em linha de conta com a especificidade do meio, as tipologias e capacidades de acolhimento das infraestruturas para a prática, o modelo de financiamento a adotar e os interesses da direção da instituição que o viabiliza.

\section{Bibliografia}

Balyi, I. (1993). Long-term athlete development: trainability in childhood and adolescence. Olympic Coach, 16, 4-9.

Bompa, T. (1999). Periodization: Theory and Methodology of Training ( $4^{\mathrm{a}}$ ed.). Champaign, IL: Human Kinetics.

Carvalho, J.H. (1991). A escola do ténis do CETO. Revista do Ténis, Oeiras.

Davids, K., Savelsbergh, G.J.P., \& Miyahara, M. (2010). Identifying constraints on children with movement difficulties. Implications for pedagogues and clinicians. In I. Renshaw, K. Davids, G.J.P. Savelsbergh (Eds.), Motor learning in Practice (pp. 173-186). London: Routledge.

DGIDC-Gabinete Coordenador do Desporto Escolar (2007/2008 e 2008/2009). Programa do Desporto Escolar. Recuperado de http://www.desportoescolar.minedu.pt/downloadFile.aspx?id=616

Farrow, D., \& Reid, M. (2010). Skill acquisition in tennis. Equipping learners for success. In I. Renshaw, K. Davids, G.J.P. Savelsbergh (Eds.), Motor Learning in Practice. A Constraints-Led Approach (pp. 231-240). London: Routledge.

Federação Portuguesa de Ténis (1999). Manipulações e Jogos de Raquetes. Lisboa: Ministério da Educação.

Fédéracion Française de Tennis. (1987). L'étection et les test de l'école de tennis, document $n .^{\circ} 1$. Paris: Fédération Française de Tennis.

Fédération Française de Tennis (1989). L'organization Fédérale de L'enseignement dans le Club (Doc. 3). Paris: Fédération Française de Tennis. 
Lee, M. (1999). O desporto para os jovens ou os jovens para o desporto? In Seminário Internacional Treino de Jovens (pp. 123-134). Lisboa: Secretaria de Estado do Desporto.

Martin, D. (2001). Manual de metodologia del entrenamiento deportivo. Barcelona: Editorial Paidotribo.

Mintzberg, H. (1989). Mintzberg on Management - Inside Our Strange World of Organizations. New York: The Free Press.

Pires, G. (1994). Do jogo ao Desporto. Para uma dimensão organizacional do conceito de desporto. Um projecto Pentadimensional de Geometria Variável. Ludens, 14, 43-60.

Pires, G. (2007). Agôn - Gestão do Desporto. Porto: Porto Editora.

Real Federación Española de Ténis (2003a). Entrenador - Organización, Planificación y Programación de las Escuelas de Tenis. Madrid: Real Federación Española de Ténis.

Real Federación Española de Ténis (2003b). Monitor Nacional de Ténis - Organización, Planificación y Programación de las escuelas de Ténis. Madrid: Real Federación Española de Ténis.

Schöllhorn, W.I., Mayer-Kress, Newell, K.M., \& Michelbrink, M. (2008). Time scales of adaptive behaviour and motor learning in the presence of stochastic perturbations. Human Movement Science, 28, 319-33.

United Tennis Association (2004). Coaching Tennis Sucessfully (2 ${ }^{\text {nd }}$ ed.). Champaign, IL: Human Kinetics.

Vickers, J.N. (1990). Instructional Design for Teaching Physical Activities - A knowledge Structures Approach. Champaign, IL: Human Kinetics. 